\title{
Predictors of Omphalitis among Spontaneous Vertex Delivery Neonates in Nakuru County Hospital, Kenya
}

\author{
${ }^{1}$ Lucy Kinanu*, ${ }^{2}$ James Mwaura, ${ }^{3}$ Anne Karani \\ University of Nairobi School of Nursing
}

\begin{abstract}
Background: Omphalitis (umbilical cord infection) among new-borns is common and a major cause of neonatal deaths in developing countries. Annually, about 4 million neonatal deaths occur around the world. Of these, $>30 \%$ are caused by infections that mainly from umbilical cord. Cord care practices may directly contribute neonatal infections; largely contributing tothis was part data from a larger randomized trial among 540 participant's neonatal deaths. Cord infections are more prevalent in developing countries because of the high rates of poverty and unhygienic practices.

Objective: To determine the predictors of omphalitis among neonates in Nakuru County Hospital, Kenya. Methodology This was part data from a larger randomized trial among 540 participants.

Findings: The prevalence of Omphalitis was 23.1. Babies whose mothers' did not wash hands when eating had 2.14 times risk of developing cord infection compared to those babies whose mothers' indicated otherwise $[\mathrm{AOR}=2.14 ; 95 \% \mathrm{CI}=1.28-3.57 ; \mathrm{p}=0.004]$. Likewise, babies whose mothers' never folded diapers backwards were twice likely over those who did to develop cord infection [AOR=1.88; $95 \% \mathrm{CI}=1.03-3.44 ; \mathrm{p}=0.039]$. Babies whose mothers' stayed in different rooms had 7.35 times risk of developing cord infection $[\mathrm{AOR}=7.35 ; 95 \% \mathrm{CI}=3.40-15.91 ; \mathrm{p}<0.001]$ over those roomed in.

Conclusion and recommendation: Maternal and caretakers hand hygiene, folding back of diapers and rooming in are critical in cord infection prevention. Health education to mothers and care takers on the importance of hand hygiene, diaper application and importance of rooming in is recommended to minimise omphalitis and consequential morbidity.
\end{abstract}

Keywords: Diaper application, Hand hygiene, Rooming-in, Omphalitis.

\section{Introduction}

Newborns are a vulnerable group needing more attention and care. Globally, two thirds of total infant deaths comprise newborns and 99\% of these deaths are concentrated in Sub-Saharan Africa and the South East Asian region (Mullany et al., 2009). Worldwide, 2.6 million neonatal deaths occurred in 2016, translating to approximately 7,000 deaths daily (UNICEF, 2019). Infections are a major contributor to newborn deaths in developing countries with majority of them starting as umbilical cord infection then becoming systemic. Omphalitis, the infection of the umbilical cord and defined as pus discharge, redness with or without pus and swelling of umbilical cord, has remained a public health problem in developing and resource-poor countries where it causes neonatal illnesses and deaths (Imdad et al., 2013). For this reason, Umbilical Cord Care (UCC) continues to be an active subject in scientific research.

Currently, there is substantial disagreement in the recommendations made by health providers to caregivers for UCC. These recommendations are often based on custom or personal beliefs and not supported by evidence (Zupan et al., 2004). Harmful traditional practices during cord cutting, tying, application of different substances to the fresh umbilical stump and unhygienic handling of the neonate by the care takers may contribute to the entrance of infectious micro-organisms (Shariff et al., 2016) leading to consequent morbidity and mortality.

Thus, understanding the proximal, intermediate and distal determinants of omphalitis is critical in prevention of the same. For the current study, we sought to understand the intermediate determinants of omphalitis 
which include hygiene-related practices that contribute to infections and mortality mainly after discharge from the health facility. These include type of infant-bathing practices, manner diapers are folded, attendants' hand-washing practices, Rooming in which leads to skin to skin between mother and newborn, and thermal care of the newborn (Mullany et al., 2009). Proper hand hygiene is documented as the single most important, simplest, and least expensive means of reducing the spread of infections (Mathur et al., 2011).

\section{Methods}

Setting: The study was conducted in Nakuru County Hospital, a level 5 facility in Kenya. The hospital averages 1000 spontaneous vertex deliveries (SVD) and 300 caesarean sections a month. This facility had the highest early neonatal mortality rate in 2014 in Kenya (36\%), with neonatal sepsis a great contributor (KDHS, 2014)

Study design and participants: The larger study from which this data was drawn was a randomized controlled trial comprising 540 participants systematically drawn. Participants were healthy term SVD newborns (38-42 weeks gestation). They had to be within twelve hours post-delivery, free from congenital anomalies, and weigh 2500-4000 grams, and Apgar score $\geq 8$ at first minute. Participants had to have nothing applied to the umbilical cord stump yet, roomed-in with their mothers, and breast fed within one hour. Informed consent was gotten from care takers. Neonates requiring immediate neonatal intensive care, born before arrival to hospital, with malformations, or referred from other hospitals with labour complications or other medical conditions were exempted.Demographic information and history relevant to the study were collected from the care-taker, other family members and from obstetrics record using a structured questionnaire. The tool further collected information on cord care practices, initiation of breastfeeding, thermal care, any substance application on the cord, methods used to care for the cord, appropriate application of diaper and washing hands. Additionally, umbilical cord-swab were taken from the base of the umbilical cord within twelve hours of delivery before any other cord care commencement and later on the seventh. The specimens were collected by a trained laboratory technologist using a dry sterile swab soaked in Amies transport medium (Oxiod, England), labelled with baby's code and delivery date. They were transported in Stuart's medium (Merck - Germany) and sent to bacteriology laboratory within one hour of collection. All specimens were cultured in the blood agar and MacConkey agar plates (Merck Germany) and incubated for $24-48$ hours at $37^{\circ} \mathrm{C}$. Bacterial growth was monitored to identify omphalitis causing organisms in the infected samples.

New-borns were followed up at day 3, 14, 21 and 28 for any signs of umbilical cord infection and features of sepsis during the total neonatal period. On day seven all the neonates were brought back to the facility for a follow-up umbilical cord swab and examination of the umbilical cord stump. During and immediately after the hospital stay, mothers were given health messages on how to care for the cord stump and how to note signs of umbilical infection at home which included redness, foul smell, or pass discharge and were asked to report to the researcher if any such signs were noticed. Objective identification of omphalitis in this study was defined as pathogenic bacterial culture in the umbilical cord swab within twenty four hours and /or on the follow up on the seventh day showing single isolates or predominantly single isolates with or without any physical signs on the skin.

Data analysis: Raw data from Kobo Collect were coded and entered into Microsoft Excel and transported exported into Statistical Package for Social Sciences (SPSS) version 22 for analysis. Descriptive statistics using frequency and proportions were computed to describe the basic attributes of the respondents as well as the occurrence of omphalitis. Chi-square tests and logistic regressions were performed to determine whether there were significant associations between the factors studied and occurrence of omphalitis The effectiveness of the regimens were determined using multiple logistic regression by considering the variables revealed significant difference at $p<0.05$ during the descriptive comparison analysis. Accordingly, the model include the following factors: the intervention group, number of children and how to clean the umbilical cord. Backward conditional method was specified with removal at $p<0.05$.

Further, Odds ratios with corresponding $95 \%$ confidence interval were also calculated for the variables. Level of significance was set at a $\mathrm{P}$ value $<0.05$. 
Ethical considerations: The study was approved by the Institutional Review Board and permission granted by both Nakuru county and the facility administration. Informed consent was obtained from the participants' care takers. Participants who had omphalitis or those whose caretakers requested were reviewed and treated by a neonatal clinician.

\section{Results}

Omphalitis in relation to socio-demographic characteristics of mothers and neonates

There was an attrition rate of $10 \%$ from the 540 neonates to 485 atfollow-up. The prevalence of cord infection was $23.1 \%$. The highest percentage $(41.6 \%)$ of mothers were aged between 19-24 years. Most were married $(77.9 \%)$, attained secondary education $(55.1 \%)$ and were Christians (95.3\%). Highest percentage of households $(30.7 \%)$ had one child. Studied neonates were majority female $(51.8 \%$ versus $48.2 \%$ for male). All the neonates had normal Apgar score and birth weight, with majority (70.3\%) having an Apgar score of $\geq 8$ in the first one minute. About half (49.3\%) weighed 3.01 to $3.50 \mathrm{Kgs}$. Almost all (99.4\%) initiated breast feeding within one hour. However, there was no significant association between demographic characteristics of the mothers or neonates and cord infection among neonates $(p>0.05)$ as shown in Table 1.

Table 1: Demographic characteristics of the mothers and neonates stratified by cord infection status

\begin{tabular}{|c|c|c|c|c|c|c|c|c|}
\hline \multirow{2}{*}{ Variables } & \multicolumn{2}{|c|}{ Total } & \multicolumn{2}{|c|}{ Infected } & \multirow{2}{*}{$\begin{array}{l}\text { Not } \\
\mathrm{n}\end{array}$} & fected & \multirow{2}{*}{$\begin{array}{l}\chi^{2} \\
\text { value }\end{array}$} & \multirow[t]{2}{*}{ p value } \\
\hline & $\mathbf{n}$ & $\%$ & $\mathbf{N}$ & $\%$ & & $\%$ & & \\
\hline \multicolumn{9}{|l|}{ Age in years } \\
\hline $19-24$ & 202 & 41. & 50 & 24.8 & 152 & 75.2 & 0.68 & 0.877 \\
\hline $25-29$ & 141 & 29. & 32 & 22.7 & 109 & 77.3 & & \\
\hline $30-34$ & 97 & 20. & 21 & 21.6 & 76 & 78.4 & & \\
\hline 35 and above & 45 & 9.3 & 9 & 20.0 & 36 & 80.0 & & \\
\hline \multicolumn{9}{|l|}{ Marital Status } \\
\hline Married & 378 & 77. & 87 & 23.0 & 291 & 77.0 & 0.01 & 0.940 \\
\hline Single/divorced & 107 & 22. & 25 & 23.4 & 82 & 76.6 & & \\
\hline \multicolumn{9}{|c|}{ Level of Education } \\
\hline Primary & 142 & 29. & 31 & 21.8 & 111 & 78.2 & 0.54 & 0.763 \\
\hline Secondary & 267 & 55. & 65 & 24.3 & 202 & 75.7 & & \\
\hline College & 76 & 15. & 16 & 21.1 & 60 & 78.9 & & \\
\hline \multicolumn{9}{|l|}{ Religion } \\
\hline Christian & 462 & 95. & 106 & 22.9 & 356 & 77.1 & 0.12 & 0.727 \\
\hline Muslim & 23 & 4.7 & 6 & 26.1 & 17 & 73.9 & & \\
\hline \multicolumn{9}{|c|}{ Number of children } \\
\hline One & 149 & 30. & 30 & 20.1 & 119 & 79.9 & 3.12 & 0.538 \\
\hline Two & 130 & 26. & 32 & 24.6 & 98 & 75.4 & & \\
\hline Three & 138 & 28. & 37 & 26.8 & 101 & 73.2 & & \\
\hline Four & 38 & 7.8 & 6 & 15.8 & 32 & 84.2 & & \\
\hline Five and above & 30 & 6.2 & 7 & 23.3 & 23 & 76.7 & & \\
\hline \multicolumn{9}{|l|}{ Baby's gender } \\
\hline Male & 234 & 48. & 50 & 21.4 & 184 & 78.6 & 0.76 & 0.384 \\
\hline Female & 251 & 51. & 62 & 24.7 & 189 & 75.3 & & \\
\hline Birth weight & & & & & & & & \\
\hline
\end{tabular}




\begin{tabular}{|c|c|c|c|c|c|c|c|c|}
\hline $2.50-3.00 \mathrm{Kgs}$ & 130 & 26. & 35 & 26.9 & 95 & 73.1 & 3.39 & 0.184 \\
\hline $3.01-3.50 \mathrm{Kgs}$ & 239 & 49. & 57 & 23.8 & 182 & 76.2 & & \\
\hline $3.51-4.00 \mathrm{Kgs}$ & 116 & 23. & 20 & 17.2 & 96 & 82.8 & & \\
\hline \multicolumn{9}{|c|}{ APGAR score in the first one minute } \\
\hline 8 & 138 & 28. & 34 & 24.6 & 104 & 75.4 & 0.38 & 0.829 \\
\hline 9 & 341 & 70. & 77 & 22.6 & 264 & 77.4 & & \\
\hline 10 & 6 & 1.2 & 1 & 16.7 & 5 & 83.3 & & \\
\hline \multicolumn{9}{|c|}{ Initiation of Breast Feeding } \\
\hline$<1$ hour & 482 & 99. & 112 & 23.2 & 370 & 76.8 & 0.91 & 0.341 \\
\hline$>1$ hour & 3 & 0.6 & 0 & 0.0 & 3 & 100. & & \\
\hline * Significance & & & & & & & & \\
\hline
\end{tabular}

\section{Omphalitis in relation to socio-economic factors}

More than half $(53.6 \%)$ of the mothers were unemployed and $90.5 \%$ earned <Kshs 15000 per month. This, however, had no statistical association with cord infection $(p>0.05)$. Although majority (66.4\%) of the mothers had permanent housing, $82.5 \%$ were rental. Still, this had no significant association with cord infection among the neonates $(p>0.05)$. Sixty two $(61.6 \%)$ percent used pit latrines but proportions of cord infection were higher $(p=0.026)$ among those using flash toilet. This and other socio-economic factors studies are presented in Table 2.

\section{Omphalitis in relation to obstetric factors}

All the mothers attended antenatal care (ANC) and 56.7\% attended four times and above, but there was no significant association with cord infection $(p=0.680)$. Similarly, all had normal gestational age during delivery with the highest percentage of $37-38$ weeks $(43.1 \%)$ but this too did not associate with cord infection $(p=0.460)$. All other obstetric factors had no association with cord infection as shown in Table 3.

Table 2: Omphalitis in relation to socio-economic factors

\begin{tabular}{|c|c|c|c|c|c|c|c|c|}
\hline \multirow{2}{*}{ Variables } & \multicolumn{2}{|c|}{ Total } & \multicolumn{2}{|c|}{ Infected } & \multicolumn{2}{|c|}{ Not infected } & \multirow{2}{*}{$\begin{array}{l}\chi^{2} \\
\text { valu } \\
\text { e }\end{array}$} & \multirow{2}{*}{$p$ value } \\
\hline & $\mathbf{n}$ & $\%$ & $\mathbf{n}$ & $\%$ & $\mathbf{N}$ & $\%$ & & \\
\hline \multicolumn{9}{|l|}{ Occupation } \\
\hline Permanent employment & 37 & 7.6 & 7 & 18.9 & 30 & 81.1 & 1.19 & 0.551 \\
\hline Self/causal employment & 188 & 38.8 & 48 & 25.5 & 140 & 74.5 & & \\
\hline Not employed & 260 & 53.6 & 57 & 21.9 & 203 & 78.1 & & \\
\hline \multicolumn{9}{|c|}{ Monthly income in Shillings } \\
\hline 15,000 and less & 439 & 90.5 & 103 & 23.5 & 336 & 76.5 & 0.48 & 0.786 \\
\hline 20,000 & 13 & 2.7 & 3 & 23.1 & 10 & 76.9 & & \\
\hline 30,000 and above & 33 & 6.8 & 6 & 18.2 & 27 & 81.8 & & \\
\hline \multicolumn{9}{|l|}{ Nature of your house } \\
\hline Permanent & 322 & 66.4 & 82 & 25.5 & 240 & 74.5 & 3.46 & 0.178 \\
\hline Semi-permanent & 112 & 23.1 & 19 & 17.0 & 93 & 83.0 & & \\
\hline Temporary & 51 & 10.5 & 11 & 21.6 & 40 & 78.4 & & \\
\hline \multicolumn{9}{|l|}{ House ownership } \\
\hline Self-owned & 85 & 17.5 & 16 & 18.8 & 69 & 81.2 & 1.06 & 0.304 \\
\hline Rented & 400 & 82.5 & 96 & 24.0 & 304 & 76.0 & & \\
\hline
\end{tabular}




\begin{tabular}{|l|l|l|l|l|l|l|l|l|}
\hline Source of water & & & & & & & & \\
\hline Piped & 378 & 77.9 & 84 & 22.2 & 294 & 77.8 & 3.25 & 0.197 \\
\hline Buying & 48 & 9.9 & 16 & 33.3 & 32 & 66.7 & & \\
\hline $\begin{array}{l}\text { Others (rain water and } \\
\text { Type of toilet }\end{array}$ & 59 & 12.2 & 12 & 20.3 & 47 & 79.7 & & \\
\hline Flash & 186 & 38.4 & 53 & 28.5 & 133 & 71.5 & 4.96 & $\mathbf{0 . 0 2 6}$ \\
\hline Pit & 299 & 61.6 & 59 & 19.7 & 240 & 80.3 & & \\
\hline * Significance at $\mathrm{p}<0.05$ bolded & & & & & & \\
\hline
\end{tabular}

Table 3: Obstetric factors stratified by umbilical cord infection

\begin{tabular}{|c|c|c|c|c|c|c|c|c|}
\hline \multirow{2}{*}{ Variables } & \multicolumn{2}{|c|}{ Total } & \multicolumn{2}{|c|}{ Infected } & \multicolumn{2}{|r|}{ infected } & \multirow{2}{*}{$\begin{array}{l}\chi^{2} \\
\text { value }\end{array}$} & \multirow{2}{*}{ p value } \\
\hline & $\mathbf{n}$ & $\%$ & $\mathbf{n}$ & $\%$ & $\mathbf{N}$ & $\%$ & & \\
\hline \multicolumn{9}{|l|}{ Number of ANC visits } \\
\hline Once & 15 & 3.1 & 5 & 33.3 & 10 & 66.7 & 1.51 & 0.680 \\
\hline Twice & 55 & 11.3 & 12 & 21.8 & 43 & 78.2 & & \\
\hline Thrice & 140 & 28.9 & 29 & 20.7 & 111 & 79.3 & & \\
\hline Four times and above & 275 & 56.7 & 66 & 24.0 & 209 & 76.0 & & \\
\hline \multicolumn{9}{|c|}{ Gestation during delivery } \\
\hline 37 to 38 weeks & 209 & 43.1 & 43 & 20.6 & 166 & 79.4 & 1.55 & 0.460 \\
\hline 29 to 40 weeks & 206 & 42.5 & 50 & 24.3 & 156 & 75.7 & & \\
\hline 41 to 42 weeks & 70 & 14.4 & 19 & 27.1 & 51 & 72.9 & & \\
\hline \multicolumn{9}{|l|}{ Duration of labour } \\
\hline$<8$ hours & 44 & 9.1 & 9 & 20.5 & 35 & 79.5 & 0.53 & 0.912 \\
\hline $8-10$ hours & 117 & 24.1 & 27 & 23.1 & 90 & 76.9 & & \\
\hline 11-14 hours & 174 & 35.9 & 43 & 24.7 & 131 & 75.3 & & \\
\hline 15 hours and above & 150 & 30.9 & 33 & 22.0 & 117 & 78.0 & & \\
\hline \multicolumn{9}{|c|}{ Duration of membrane rupture } \\
\hline One hour & 79 & 16.3 & 19 & 24.1 & 60 & 75.9 & 0.12 & 0.989 \\
\hline Two hours & 171 & 35.3 & 39 & 22.8 & 132 & 77.2 & & \\
\hline Three hours & 211 & 43.5 & 49 & 23.2 & 162 & 76.8 & & \\
\hline Four hours & 24 & 4.9 & 5 & 20.8 & 19 & 79.2 & & \\
\hline \multicolumn{9}{|l|}{ Mode of delivery } \\
\hline SVD(normal) & 484 & 99.8 & 112 & 23.1 & 372 & 76.9 & 0.30 & 0.583 \\
\hline Caesarian & 1 & 0.2 & 0 & 0.0 & 1 & 100.0 & & \\
\hline \multicolumn{9}{|l|}{ Maternal HIV status } \\
\hline Negative & 427 & 88.0 & 99 & 23.2 & 328 & 76.8 & 0.02 & 0.896 \\
\hline Positive & 58 & 12.0 & 13 & 22.4 & 45 & 77.6 & & \\
\hline
\end{tabular}


* Significance at $\mathrm{p}<0.05$

\section{Omphalitis in relation to umbilical cord care practices}

Majority (89.5\%) of the mothers always washed hands after visiting toilet. Cord infections were more among those who did not, but this was not significant $(p=0.138)$. A large percentage $(96.3 \%)$ reported washed hands after changing the baby but this too was not significant $(p=0.631)$. However, they were not statistically significant with cord infection $(p>0.05)$. Of the total, $69.1 \%$ were not washing hands when eating and this was significantly more among neonates with cord infection $(p=0.003)$. Most $(86.6 \%)$ of the babies had their diaper folded backwards and cord infection was significantly higher among babies whose diaper was not folded backwards $(p=0.012)$. Even though a large number $(93.2 \%)$ of the mothers roomed in with the baby, cord infections were still significantly more among babies whose mothers were not always staying in the same room $(p<0.001)$. Table 4 summarizes the practices that could influence cord infections.

\section{Predictors of omphalitis among neonates}

After considering eight factors with $p<0.2$ altogether using binary logistic regression by specifying 'backward LR'method with removal at $p<0.05$, three factors remained in the last model (Table 5). Babies whose mothers' were not washing hands when eating had 2.14 times higher risk of developing cord infection compared to those whose mothers' indicated otherwise [AOR=2.14;95\% $\mathrm{CI}=1.28-3.57 ; p=0.004$ ]. Likewise, babies whose mothers' did not fold the diaper backwards were twice likely to have cord infection [AOR $=1.88 ; 95 \% \mathrm{CI}=1.03-3.44 ; p=0.039$ ] compared to those whose mothers' folded diapers backwards. On roomed-in babies had 7.35 times higher risk of developing cord infection [AOR=7.35; 95\%CI=3.40 $15.91 ; p<0.001]$ compared to roomed-in babies.

Table 4: Umbilical cord care practices based on cord infection status

\begin{tabular}{|c|c|c|c|c|c|c|c|c|}
\hline \multirow{2}{*}{ Variables } & \multicolumn{2}{|c|}{ Total $(\mathrm{N}=485)$} & \multicolumn{2}{|c|}{ Infected $(\mathrm{N}=112)$} & \multirow{2}{*}{$\begin{array}{l}\text { Not } \\
\text { n }\end{array}$} & infected & \multirow{2}{*}{$\begin{array}{l}\chi^{2} \\
\text { value }\end{array}$} & \multirow{2}{*}{ p value } \\
\hline & $\mathbf{n}$ & $\%$ & $\mathbf{n}$ & $\%$ & & $\%$ & & \\
\hline \multicolumn{9}{|c|}{ Washing hands after visiting toilet } \\
\hline No & 51 & 10.5 & 16 & 31.4 & 35 & 68.6 & 2.20 & 0.138 \\
\hline Yes & 434 & 89.5 & 96 & 22.1 & 338 & 77.9 & & \\
\hline \multicolumn{9}{|c|}{ Washing hands after changing the baby } \\
\hline No & 18 & 3.7 & 5 & 27.8 & 13 & 72.2 & 0.23 & 0.631 \\
\hline Yes & 467 & 96.3 & 107 & 22.9 & 360 & 77.1 & & \\
\hline \multicolumn{9}{|c|}{ Washing hands when eating } \\
\hline No & 335 & 69.1 & 90 & 26.9 & 245 & 73.1 & 8.68 & 0.003 \\
\hline Yes & 150 & 30.9 & 22 & 14.7 & 128 & 85.3 & & \\
\hline \multicolumn{9}{|c|}{ Washing hands when cooking } \\
\hline No & 288 & 59.4 & 62 & 21.5 & 226 & 78.5 & 0.98 & 0.323 \\
\hline Yes & 197 & 40.6 & 50 & 25.4 & 147 & 74.6 & & \\
\hline \multicolumn{9}{|c|}{ Methods/ways of washing hands } \\
\hline On a basin & 428 & 88.2 & 100 & 23.4 & 328 & 76.6 & 2.49 & 0.288 \\
\hline On basin and tap & 35 & 7.2 & 5 & 14.3 & 30 & 85.7 & & \\
\hline Tap & 22 & 4.5 & 7 & 31.8 & 15 & 68.2 & & \\
\hline \multicolumn{9}{|c|}{ How to clean the umbilical cord } \\
\hline Clean & 275 & 56.7 & 59 & 21.5 & 216 & 78.5 & 1.11 & 0.573 \\
\hline Clean with boiled & 63 & 13.0 & 17 & 27.0 & 46 & 73.0 & & \\
\hline
\end{tabular}




\begin{tabular}{|l|l|l|l|l|l|l|l|l|}
\hline Clean with wet/dry & 147 & 30.3 & 36 & 24.5 & 111 & 75.5 & & \\
\hline Application of diaper folded backwards on the baby (observe) & 13.4 & 23 & 35.4 & 42 & 64.6 & 6.39 & $\mathbf{0 . 0 1 2}$ \\
\hline No & 65 & 86.6 & 89 & 21.2 & 331 & 78.8 & & \\
\hline Yes & 420 & & & & & \\
\hline Always staying with the in the same room & 6.8 & 21 & 63.6 & 12 & 36.4 & 32.77 & $<\mathbf{0 . 0 0 1}$ \\
\hline No & 33 & 93.2 & 91 & 20.1 & 361 & 79.9 & & \\
\hline Yes & 452 & & & & & & \\
\hline
\end{tabular}

Table 5: Multivariable analysis for factors associated with the occurrence of cord infection

\begin{tabular}{|c|c|c|c|c|c|c|c|c|}
\hline \multirow[b]{2}{*}{ Variables } & \multirow{2}{*}{ COR } & \multicolumn{2}{|l|}{$95 \% \mathrm{CI}$} & \multirow{2}{*}{$\begin{array}{l}\mathbf{P} \\
\text { value* }^{*}\end{array}$} & \multirow{2}{*}{ AOR } & \multicolumn{2}{|l|}{$95 \% \mathrm{CI}$} & \multirow{2}{*}{$\begin{array}{l}\mathbf{P} \\
\text { value }^{*}\end{array}$} \\
\hline & & Lower & Upper & & & Lower & Upper & \\
\hline \multicolumn{9}{|l|}{ Birth weight } \\
\hline $2.50-3.00 \mathrm{Kgs}$ & 1.77 & 0.95 & 3.28 & 0.071 & 1.97 & 0.89 & 3.88 & 0.069 \\
\hline $3.01-3.50 \mathrm{Kgs}$ & 1.5 & 0.85 & 2.65 & 0.158 & 1.66 & 0.90 & 3.07 & 0.108 \\
\hline $3.51-4.00 \mathrm{Kgs}$ & Ref & & & & Ref & & & \\
\hline \multicolumn{9}{|l|}{ Nature of the house } \\
\hline Permanent & 1.24 & 0.61 & 2.53 & 0.551 & 0.98 & 0.42 & 2.29 & 0.963 \\
\hline Semi-permanent & 0.74 & 0.32 & 1.7 & 0.483 & 0.53 & 0.21 & 1.34 & 0.180 \\
\hline Temporary & Ref & & & & Ref & & & \\
\hline \multicolumn{9}{|l|}{ Source of water } \\
\hline Piped & 1.12 & 0.57 & 2.21 & 0.745 & 0.71 & 0.31 & 1.60 & 0.404 \\
\hline Buying & 1.96 & 0.82 & 4.69 & 0.131 & 2.19 & 0.84 & 5.68 & 0.108 \\
\hline Others (rain water and & Ref & & & & Ref & & & \\
\hline \multicolumn{9}{|l|}{ Type of toilet } \\
\hline Flash & 1.62 & 1.06 & 2.49 & 0.027 & 1.61 & 0.93 & 2.80 & 0.091 \\
\hline Pit & Ref & & & & Ref & & & \\
\hline \multicolumn{9}{|c|}{ Washing hands after visiting toilet } \\
\hline No & 1.61 & 0.85 & 3.03 & 0.141 & 1.13 & 0.55 & 2.33 & 0.743 \\
\hline Yes & Ref & & & & Ref & & & \\
\hline \multicolumn{9}{|c|}{ Washing hands when eating } \\
\hline No & 2.14 & 1.28 & 3.57 & 0.004 & 2.14 & 1.25 & 3.66 & 0.006 \\
\hline Yes & Ref & & & & Ref & & & \\
\hline \multicolumn{9}{|c|}{ Application of diaper folded backwards on the baby (observe) } \\
\hline No & 2.04 & 1.16 & 3.56 & 0.013 & 1.88 & 1.03 & 3.44 & 0.039 \\
\hline Yes & Ref & & & & Ref & & & \\
\hline \multicolumn{9}{|c|}{ Always staying with the in the same room } \\
\hline No & 6.94 & 3.29 & 14.63 & $<0.001$ & 7.35 & 3.40 & 15.91 & $<0.001$ \\
\hline
\end{tabular}




\begin{tabular}{|l|l|l|l|l|l|l|l|}
\hline Yes & Ref & & Ref & & \\
\hline$*$ Significance at $\mathrm{p}<0.05$ bolded; AOR= Adjusted Odds Ratio; COR= Crude Odds Ratio CI= \\
\hline
\end{tabular}

\section{Discussion}

From our study, differing socio-demographic characteristics such as age, marital status and religion of mothers and neonates factors such as sex, Apgar score or duration to initiation of breastfeeding do not appear to relate to occurrence of omphalitis. It is noteworthy however, that high majority of mothers, for instance, were married and almost all neonates were breastfed within the first hour making comparisons with those outside this possible. Breast milk encourages growth of healthy lactobacilli and lactoferrin. It further has been found to have immunoglobulins like IgA, lysozymes and white blood cells and reduces growth of E. coli and other pathogenic bacteria, (Edmond et al., 2010). Early initiation and breast-feeding frequently provides antibodies that fight infections to the newborn (WHO 2015) hence greatly encouraged. Similarly, this study found that relates socio-economic factors, employment, level of income or even housing type and ownership do not affect umbilical cord infection for neonates. While previous studies have shown that social economic factors influence the quality of cord care and consequent outcomes (kinanu et al, 2015; Sobita et al., 2010; Ogonlesi et al., 2010), our current outcomes could have been influenced by fact that we freely supplied the materials needed for cord care among our study participants so that they did not have to use their resources for this.We however found that the fecal waste disposal methods used had effect on cord infections, where use of pit latrines appeared protective against contracting omphalitis. It is likely that when diapers are disposed off into the pit latrine there is total discard of fecal wastes that would harbor bacterial organisms unlike where family members use flush toilets and therefore may have challenges in the total disposal of diapers, causing undue contaminations in the process.

The current study demonstrates that babies whose mothers' do not wash hands when eating have 2.14 times higher risk of developing omphalitis compared to those babies whose mothers' do. Need for care takers' hand hygiene can never be over emphasized in prevention of infections. The link between hand washing and infection was established over two centuries ago (global hand washing partnership, 2015). The purpose of hand washing mainly is to prevent the spread of pathogens through physical contact. Usually two types of microbes colonize hands: the resident flora, which consists of microorganisms residing under the superficial cells of the stratum corneum and the transient flora, which colonizes the superficial layers of the skin, and is removable by routine hand hygiene. Transient microorganisms survive, but do not usually multiply on the skin. They are often acquired and transferred during direct contact with contaminated environmental surfaces and are the organisms most frequently associated with infections. Our findings are in agreement to (Blencowe et al. 2011) who indicated that maternal handwashing during the postnatal period reduced cord infections, which would translate to a reduction in all-cause neonatal mortality. Multiple literature shows that this inexpensive way of preventing neonatal infections at home and in the hospitals, and that, further reduces related mortalities, is practicable in resource-limited settings such as ours (Daniels et al, 1999; Kuti et al., 2019; WHO, 2009).

From the current work, it appears there is no association between whether mothers attended ANC and how many times they did, and the occurrence of cord infection. It is likely however that this finding may have been affected by the fact that participants' caretakers were given health messages on cord-care after delivery, so that any direct influence from what was taught or not during ANC was masked. This may have affected contribution of factors such as gestation, delivery, duration of labour, time-period since rupture of delivery, mode of delivery and maternal HIV status all which are known to influence cord infection were not significant in this study. We demonstrate that factors otherwise known to contribute to omphalitis can be reversed by health messages relating to cord care as was received by our participants, which caused our findings to differ from published works.

For predictors of omphalitis among neonates, our current findings show that neonates whose mothers' were not washing hands when eating had more than twice higher risk of developing cord infection compared to those whose mothers' washed hands. This is in agreement with existing literature that shows hand hygiene is associated with reduced infections otherwise contacted from dirt. (Mathur et al., 2011) stated "There is now undisputed evidence that strict adherence to hand hygiene reduces the risk of cross-transmission of 
infections" which further agrees with WHO "Clean Care is Safer Care" initiative. (Mullany et al., 2007) further indicated that simple, low-cost interventions like hand washing reduce neonatal infections. Other predictors from the current study included whether or not the diapers were folded backwards, with those infants whose diapers were not folded backwards twice likely to have cord infectionas far as we are aware, this is novel finding and no previous study has looked at this. Our study additionally found that non-roomedin babies had more than seven times higher risk of developing cord infection compared to roomed-in babies, providing an additional predictor of omphalitis in our population. Many studies have emphasized the importance and great need for rooming-in with benefits such as making breastfeeding easier. Several studies suggest that mothers who room-in with their babies make more milk, much sooner, breastfeed longer, and are more likely to breastfeed exclusively compared with mothers who have limited contact with their babies (Bystrova, Matthiesen, et al., 2007; Daglas et al., 2005; Declercq, Sakala, Corry and Applebaum, 2006; Fairbank et al., 2000; Flores-Huerta \& Cisneros-Silva, 1997; Mikiel-Kostyra, Mazur and Wojdan-Godek, 2005;). Furthermore babies who room-in with their mothers take in more breast milk (Bystrova, Matthiesen, et al., 2007), gain more weight per day (Yamauchi and Yamanouchi, 1990), and are less likely to develop jaundice, and other infections including omphalitis (Syafruddin et al., 1988).

There are several biological mechanisms thought to account for the relationship between exclusive breastfeeding and umbilical cord infection. Breast milk contains secretory IgA, lysozymes, white blood cells, and lactoferrin. It has been shown to promote the growth of healthy Lactobacilli and reduce the growth of E. coli and other gram-negative pathogenic bacteria (Levi et al., 2007). Early initiation and exclusive breastfeeding is associated with significant reductions in diarrhea and acute respiratory infections in neonates while other observational studies have demonstrated impact on infection specific mortality rates during the neonatal period (Edimond et al., 2006; Mullany et al., 2008). In addition, initiating breastfeeding in the first hour of life is also recognized by the WHO as an important component of protection and should be implemented as routine hospital practice in all countries in order to reduce all cause neonatal mortality. When a mother and her baby are continuously together (rooming in), the baby is exposed to the normal flora on the mother's skin, which offer great protection to the baby from becoming exposed to harmful bacteria which can predispose the baby to infection and disease (WHO, 1998), which reflects our current finding.

\section{Conclusion}

Socio-demographic and socio-economic factors do predispose to omphalitis among neonates in NakuruKenya. The type of family toilet however associates with development of omphalitis, perhaps because this affects how diapers are disposed off. Predictors of cord infections development in our set up include whether or not caretakers wash hands before eating, whether neonates are roomed-in, and how the diapers are folded.

\section{Acknowledgement;}

I wish to acknowledge Dr. Margaret Chege and Dr. Karani Magitah for their contribution in the writing of this manuscript.

\section{References}

[1.] Amare Y. (2014) umbilical cord care in Ethiopia and implications for behavioral Change: a qualitative study. BMC Int Health Hum Rights; 14(1):12.

[2.] Arifeen SE, Mullany LC, et al., (2012) the effect of cord cleansing with chlorhexidine on neonatal mortality in rural Bangladesh: acommunity-based, cluster-randomised trial. Lancet (British edition); 379(9820):1022-8.

[3.] Blencowe H, Cousens S, Mullany LC, et al. (2011) clean birth and postnatal care practices to reduce neonatal deaths from sepsis and tetanus: a systematic review and Delphi estimation of mortality effect. BMC Public Health. 11 Suppl 3, S11.

[4.] Bystrova K, Widstrom AM, Matthiesen AS, Ransjo-Arvidson AB et al., (2007) early lactation performance in primi-parous and multiparous women in relation to different maternity home practices: A randomized trial in St. Petersburg. International Breastfeeding Journal; 2:9. et al. [PMC free article] [PubMed] [Google Scholar]

[5.] Daglas M, Antoniou E, Pitselis G., et al (2005) Factors influencing the initiation and progress of breastfeeding in Greece. Clinical and Experimental Obstetrics \& Gynecology; 32(3):189-192. [PubMed] [Google Scholar] 
[6.] Declercq E. R, Sakala C, Corry M. P, and (2006) Apple Baum S. Listening to mothers II: Report of the second national U.S. survey of women's childbearing experiences New York: Childbirth Connection. [PMC free article] [PubMed] [Google Scholar]

[7.] Daniels IR, Rees BI. (1999)Handwashing: simple, but effective. Ann R CollSurg Engl; 81:117-8. [PMC free article] [PubMed] [Google Scholar]

[8.] Edmond, K.M., Kirkwood, B.R., et al., (2007) Effect of Early Infant Feeding Practices on Infection-Specific Neonatal Mortality: An Investigation of the Causal Links with Observational Data from Rural Ghana. The American Journal of Clinical Nutrition, 86, 1126-1131.

[9.] Edmond KM., Yando C., et al., (2006) Delayed Breastfeeding Initiation Increases Risk of Neonatal Mortality. Pediatrics, 117, 380-386. http://dx.doi.org/10.1542/peds.2005-1496.

[10.] Fairbank L, O'Meara S, Renfrew M, et al (2000) a systematic review to evaluate effectiveness of interventions to promote the initiation of breastfeeding. Health Technology Assessment: 4(25):171. [PubMed] [Google Scholar]

[11.] Flores-Huerta S, Cisneros-Silva I (1997) Mother-infant rooming-in and exclusive breast feeding. SaludPublica de Mexico; 39(2):110-116. [PubMed] [Google Scholar]

[12.] Imdad A., Bautist RMM.et al., (2013). Umbilical cord antiseptics for preventing sepsis and death among newborns. Cochrane Database of Systematic Reviews. JohnWiley \& Sons, Ltd 5: CD008635. DOI:10.1002/14651858.CD008635.pub2 Kenya Demographic and Health Survey (KHDS) 2014.

[13.] Kinanu, L., Odhiambo, E., et al., (2016) Cord Care Practices and Omphalitis among Neonates Aged 3 - 28 Days at Pumwani Maternity Hospital, Kenya. Journal of Biosciences and Medicines, 4, 27-36.

[14.] Kuti BP, Ognlesi TA, Oduwole O., et al., (2019) Hand hygiene for the prevention of infections in neonates Cochrane Systematic Review https://doi.org/10.1002/14651858.CD013326.

[15.] Levy, O. (2007) Innate Immunity of the Newborn: Basic Mechanisms and Clinical Correlates. Nature Reviews Immunology; 7 (379-390). http://dx.doi.org/10.1038/nri2075.

[16.] Mathur P (2011) Hand hygiene: Back to the basics of infection control Indian J Med Res; 134(5): 611-620.

[17.] Mikiel-Kostyra K., Mazur J, Wojdan-Godek E (2005) Factors affecting exclusive breastfeeding in Poland: Cross-sectional survey of population-based samples. Sozial- Und Präventivmedizin; 50(1):52-59. [PubMed] [Google Scholar]

[18.] Mullany, L. C., Darmstadt, G. L. et al. (2009). Risk of mortality subsequent to umbilical cord infection among newborns of southern Nepal: cord infection and mortality. Pediatr Infect Dis J: 28:17- 20.

[19.] Mullany LC. Katz J., et al., (2008) Breast-Feeding Patterns, Time to Initiation and Mortality Risk among New-Borns in Southern Nepal. Journal of Nutrition, 138, 599-603.

[20.] Mullany, L. C., Darmaetadt, G. L. et al. (2007). Risk factors for umbilical cord infection among newborn of southern Nepal. Am J Epidemiol; 165(2): 203-211.

[21.] Neonatal mortality [https://data.unicef.org/topic/child-survival/neonatalmortality/].

[22.] Ogunlesi, TA. and Ogunfowora, OB. (2010). Predictors of Mortality in Neonatal Septicemia in an Underresourced Setting. Journal of the National Medical Association. 2010; 102 (10) 915-920.

[23.] Shariff JA, Lee KC, et al., (2016) neonatal mortality and topical application of chlorhexidine on umbilical cord stump: a meta-analysis of randomized control trials Public Health, 139 pp. 27-35 http://dx.doi.org/10.1016/j.puhe.05.006 | Medline.

[24.] Sobita, T. (2010). The determinants of good newborn care practices in the rural areas of Nepal $U C$ Research Repositor. http://hdl.handle.net/10092/5061.

[25.] Syafruddin M, Djauhariah A. M, Dasril D (1988) a study comparing rooming-in with separate nursing. PaediatricaIndonesiana; 28(5-6):116-123. [PubMed] [Google Scholar]

[26.] UNICEF, WHO, World Bank, and United Nations (2011), Levels and Trends in Child Mortality, UNICEF, New York, NY, USA.

[27.] WHO. 2015c. WHO recommendations for prevention and treatment of maternal peripartum infections. Retrieved from Geneva, Switzerland: World Health Organisation. 
[28.] WHO. 2009b. WHO Guidelines on Hand Hygiene in Health Care. Retrieved from Geneva, Switzerland: World Health Organization.

[29.] WHO (2006) Guidelines on Hand Hygiene in Health Care. First Global Patient Safety Challenge. Clean Care is Safer Care. Available from: http://www.who.int/patientsafety/en/

[30.] WHO (2005) Guide to implementation multimodal hand hygiene improvement strategy. Available from: http://www.who.int/patientsafety/en/

[31.] WHO (1998) Evidence for the 10 steps to successful breastfeeding (rev. ed., WHO/CHD/98.9). Geneva, Switzerland: Author.

[32.] Yamauchi Y, Yamanouchi I (1990) the relationship between rooming-in/not rooming-in and breast-feeding variables. ActaPaediatricaScandinavica; 79(11):1017-1022. [PubMed] [Google Scholar]

[33.] Zupan, P. Garner, A.A. Omari (2004) Topical umbilical cord care at birth.

[34.] Cochrane Database Syst Rev, pp. CD001075. 